\title{
REVIEW ON INVESTIGATION AND OPTIMIZATION OF TURNING PROCESS PARAMETER IN WET AND MQL SYSTEM ON EN31
}

\author{
S. S. Acharya ${ }^{1}$, R. L. Karwande ${ }^{2}$ \\ ${ }^{l}$ M.E.Student, Dept. of Mechanical, M.S.S.C.E.T., Jalna, Maharashtra, India \\ ${ }^{2}$ Associate Professor, Department of Mechanical, M.S.S.C.E.T., Jalna, Maharashtra, India
}

\begin{abstract}
The big challenge of the mass production firms is concentrated for achieving high quality products with good dimensionability with high productivity, less wear on the cutting insert, less use of cutting fluid, within less time. This paper present review of an dissertation work of an investigation of turning process parameters on hard EN 31 material, for optimization of surface roughness, material removal rate, machining time in wet and minimum quantity lubrication system. The experiment will carry out by considering four controllable input variables namely cutting speed, feed rate, depth of cut and insert nose radius. This experiment will also present the relation between chip formations and controllable variables along with chip thickness and chip colors from which its effect on insert wear, quality of product can be easily found out, because of chip morphology gives indirectly the effect of it on the insert wear. In this dissertation work minimum quantity lubrication system will use for reducing the cutting zone temperature properly and very fastly. Finally comparison will carry out between wet and minimum quantity lubrication system from which one can easily indentify which system is better for higher productivity along with high surface finish. This work will also present the inventory concept in production. The design of experiment and optimization of surface roughness, material removal rate, machining time will carry out by using response surface methodology (RSM). Central composite design method will use (CCD) for the total experimental design work and its analysis and also for optimization of turning process parameter by which wastage of the machining time, power can be avoided.
\end{abstract}

Keywords-mass production, minimum quantity lubrication, inventory concept, RSM, CCD.

\section{INTRODUCTION}

In India machine tool industry made very great progress, but there main drawback is that they not running the machine tools at their optimum operating conditions so that there is loss of man power, material, time, quality along with productivity also. It has long been recognized that conditions during cutting such as feed rate, depth of cut, cutting speed, nose radius should be selected to optimize the economics of machining operations. In machine tool field turning hardened steel is valuable process. Cutting hardened steel is an interesting topic of today's industrial production and scientific research. Turning process for hard steel is preferable thing compared to grinding process. A major factor leading to the use of hard turning in place of grinding has been the development of cubic boron nitride (CBN) cutting tool insert, which enable machining of high-strength materials with a geometrically defined cutting edge. The main advantage of precision hard turning over grinding include lower production costs, higher productivity, greater flexibility, elimination of grinding fluids, and enhanced work piece quality.

In turning process, single-point cutting tool that is nothing but insert can complete the entire machining process in a single fixture, thereby reduced setup times as well as lower costs. Also there is many optionable thing to improve the turning process rather than grinding process. In recent there is big problem for all industrialist for achieving high quality products with more productivity within less machining time which affects on surface roughness during turning of hardened steel. Even rough surfaces wear more quickly \& have high friction coefficient than smooth surfaces. As the surface roughness increases then customer demand \& quality of product goes on decreasing. So that there should be bridge between quality and productivity. In short there should be such optimum condition on which tool wear rate is minimum, maximum productivity with maximum quality within less time. Generally hard turning requires large quantities of coolants and lubricants. The cost associated with storage and disposal of coolants and lubricants increases the total cost of production considerably. Conventional cutting fluid application fails to penetrate the chip-tool interface and thus cannot remove heat effectively due to which there is loss of surface finish and also loss of tool life. To overcome this problem there are some solutions. Some of these alternatives are dry machining and machining with minimal fluid application. Dry machining is now of great interest and actually, they meet with success in the field of environmentally friendly manufacturing. However, they are sometimes less effective when higher machining efficiently, better surface finish quality and serve cutting conditions are required. Minimal fluid application refers to the use of cutting fluids of only a minute amount typically of flow rate of 50 to $500 \mathrm{ml} /$ hour. The concept of minimal fluid application sometimes referred to as near dry lubrication or micro lubrication. 


\section{LITERATURE REVIEW}

D.V. Lohar have evaluated the performance of MQL system during turning on hard AISI 4340 material by using Taguchi method. They have used the feed rate, cutting speed, depth of cut as process parameter for analysis of cutting forces, surface roughness, cutting temperature \& tool wear. They have found that cutting force \& temperature is less in MQL system Compared to the dry \& wet lubrication system. The surface finish is also high in case of MQL system. [1]

L B Abhang investigated the effect of MQL during turning of EN 31 alloy steel for analysis of cutting temperature, cutting force, surface roughness. They found that quality of product as well as tool life gets improved. [2]

Y.B. Kumbhar investigated tool life and surface roughness optimization of PVD TiAlN/TiN coated carbide inserts in semi hard turning of hardened EN31 alloy steel under dry cutting conditions using taguchi method. They have concluded that the feed rate was the most influential factor on the surface roughness and tool life. [3]

Ravinder Tonk, have investigated the effects of the parametric variations in turning process of En31 alloy steel. Taguchi's robust design methodology has been used for statistical planning of the experiments. Experiments were conducted on conventional lathe machine in a completely random manner to minimize the effect of noise factors present while turning EN31 under different experimental conditions. The analysis of results shows that input parameter setting of cutting tool as carbide, cutting condition as dry, spindle speed at $230 \mathrm{rpm}$, feed at $0.25 \mathrm{~mm} / \mathrm{rev}$ and depth of cut at $0.3 \mathrm{~mm}$ has given the optimum results for the thrust force and input parameter setting of cutting tool as HSS, cutting fluid as soluble oil, spindle speed at $230 \mathrm{rpm}$, feed at $0.25 \mathrm{~mm} / \mathrm{rev}$ and depth of cut at $0.3 \mathrm{~mm}$ have been given the optimum results for the feed force when EN31 was turned on lathe. [4]

M.A.H. Mithu have evaluated the effect of minimum quantity lubrication on turning AISI 9310 alloy steel using vegetable oil based cutting fluid. They have found that chiptool interface temperature as well as tool wear gets reduced. [5]

Nikhil Ranjan Dhar evaluated the performance of MQL system on tool wear, surface roughness and dimensional deviation in turning AISI-4340 steel by using cutting speed, feed rate, depth of cut as controllable variables. They improved the tool life in MQL system. [6]

\subsection{Literature Outcome}

From the literature review, it is observed that less research work has been seen for En31 Alloy Steel in CNC turning by the use of MQL system. Also very less work has been reported for optimization of surface roughness, material removal rate \& machining time on En 31 material. Also optimization of turning process parameter in MQL system \& comparison it with wet turning is to be reported to much less. Chip chart is also new concept that has reported for EN 31 material in MQL system and wet system is too much less from which one can easily predict tool life, surface finish. Again no one can do an experiment by varying all controllable parameter in single experiment. I will conduct near about thirty experiment by varying each variable that is cutting speed, feed rate, depth of cut $\&$ insert nose radius along with lubrication environment in each and every experiment.

\section{EXPERIMENTAL DETAILS}

\subsection{Work Piece}

The work piece material will EN-31 steel in the form of round bars of $40 \mathrm{~mm}$ diameter and length of $100 \mathrm{~mm}$ axial cutting length. The composition of material is $0.9-1.2 \% \mathrm{C}$, $0.10-0.35 \% \mathrm{Si}, 0.3-0.75 \% \mathrm{Mn}, 1-1.6 \% \mathrm{Cr}, 0.025 \% \mathrm{Co}$, $0.05 \% \mathrm{~S}$ and $0.05 \% \mathrm{P}$. Application of this material with its properties are used to make axels, gears, camshafts, driving pinion and link components for transportation and energy products as well as many applications in general mechanical engineering. The work piece of EN-31 was firstly hardened followed by oil quenching at a temperature of $850^{\circ} \mathrm{C}$ to achieve a hardness of $60 \mathrm{HRC}$ throughout. A rough turning pass was conducted initially to eliminate the run out of the work piece, after that diameter obtained for experimentation is approximately $25 \mathrm{~mm}$.

\subsection{Cutting Tool}

CBN insert CNMG 120408, CNMG 120404, CNMG 120401.2 is selected along with tool holder PCLNL 2525R 12

\subsection{Machine}

A high speed precision CNC Lathe (HASS - MAKE) having Maximum turning diameter $270 \mathrm{~mm}$ Height of centres over carriage $60 \mathrm{~mm}$ Maximum turning length: $409 \mathrm{~mm}$ Headstock A2-4 / CAMLOCK D1-3" Spindle speed 50 $5,000 \mathrm{rev} / \mathrm{min}$ AC motor drive: Power consumption $7.5 \mathrm{~kW}$ Transverse stroke, X-axis $190 \mathrm{~mm}$ AC motor drive: intermittent torque 4 to $14 \mathrm{Nm}$ Longitudinal stroke, Z-axis $415 \mathrm{~mm}$ Number of fixed tool stations/rotating tool stations $-8$

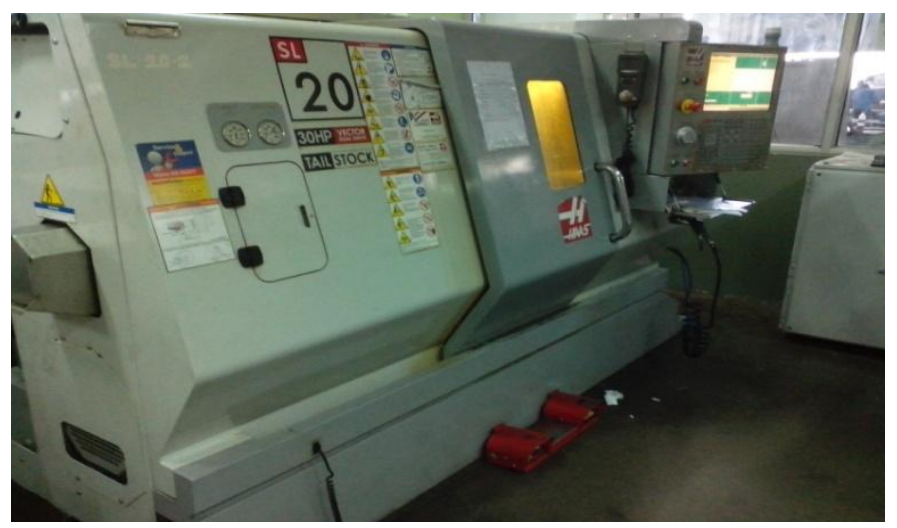

Fig-1 CNC Lathe Machine 


\subsection{Cutting Fluid}

Blasocut oil will supply as jet of cutting fluid with compressed air at 5 bar pressure. The supply is directed at tool-work piece contact zone.

\subsection{Process Parameter}

Cutting speed, feed rate, depth of cut, wet \& MQL system, Insert nose radius. All this parameter are used at there lowest and highest level by considering machine specification.

\subsection{Response Variables}

Material removal rate, surface roughness, machining time, chip morphology.

\section{OBJECTIVES}

1. To investigate the effect of different cutting parameters like depth of cut, feed rate cutting speed on EN 31 material.

2. To find out the optimum cutting condition.

3. To improve productivity of products.

4. To optimize surface roughness, MRR, Machining time.

5. To observe the chip thickness, its color.

6. To observe the effect of insert nose radius.

7. To observe \& compare the wet \& MQL system.

\section{RESEARCH METHODOLOGY}

In that dissertation work to carry out design \& experiment analysis I will use, RSM (Response surface methodology) (ccd-method) in Minitab16. Availability resources \& experimentation will carry out in INDOGERMAN TOOL ROOM.

\section{CONCLUSIONS}

Hence it is concluded that feed rate has significant effect on surface roughness. Depth of cut is a major parameter to control the tool wear. From the review of different journal papers it is concluded that minimum quantity lubrication system is a better than wet lubrication system.

\section{REFERENCES}

[1] D. V. Lohar, "Performance Evaluation of Minimum Quantity Lubrication (MQL) using CBN Too during Hard Turning of AISI 4340 and its Comparison with Dry and Wet Turning", Bonfring International Journal of Industrial Engineering and Management Science, Vol. 3, No. 3, September 2013.

[2] L. B. Abhang, "EXPERIMENTAL INVESTIGATION OF MINIMUM QUANTITY LUBRICANTS IN ALLOY STEEL TURNING”, International Journal of Engineering Science and Technology Vol. 2(7), 2010, 3045-3053.

[3] Y. B. Kumbhar, "TOOL LIFE AND SURFACE ROUGHNESS OPTIMIZATION OF PVD TiAlN/TiN MULTILAYER COATED CARBIDE
INSERTS IN SEMI HARD TURNING OF HARDENED EN31 ALLOY STEEL UNDER DRY CUTTING CONDITIONS", International Journal of Advanced Engineering Research and Studies EISSN2249-8974

[4] Ravinder Tonk, "Investigation of the Effects of the Parametric Variations in Turning Process of En31 Alloy", International Journal on Emerging Technologies 3(1): 160-164(2012) ISSN No. 09758364

[5] M.A.H. Mithu ,"Effects of minimum quantity lubrication on turning AISI 9310 alloy steel using vegetable oil based cutting fluid" Journal of Materials Processing Technology 209 (2009) 5573-5583

[6] Nikhil Ranjan Dhar ,"Effect of Minimum Quantity Lubrication (MQL) on Tool Wear, Surface Roughness and Dimensional Deviation in Turning AISI-4340 Steel", G.U. Journal of Science 20(2): 23 32 (2007)

\section{BIOGRAPHIE}

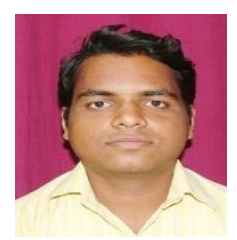

My name is Shekhar S. Acharya. Completed B.E. (Mech.) in 2012 from MSSCET, Jalna. Now studying in M.E. (Mech.) IInd Year from the same college. I have two years experience in teaching filed. My interest is in creation or innovation in a manufacturing processes. 